\title{
The challenges and optimization of cell-based therapy for cardiovascular disease

\author{
Shiyue Xu, ${ }^{1,2 *}$ Yumin Qiu, ${ }^{1 *}$ Jun Tao $^{1}$ \\ 'Department of Hypertension and Vascular Disease, The First Affiliated Hospital, Sun Yat-sen University, \\ Guangzhou 510080, Guangdong Province, China; \\ ${ }^{2}$ Department of Biomedical Engineering, Molecular Cardiology Program, School of Medicine and School of
} Engineering, University of Alabama at Birmingham. \\ ABSTRACT \\ With the hope of achieving real cardiovascular repair, cell-based therapy raised as a promising strategy for the treatment of cardiovascular disease (CVD) in the past two decades. Various types of cells have been studied for their reparative potential for CVD in the ensuing years. Despite the exciting results from animal experiments, the outcome of clinical trials is unsatisfactory and the development of cell-based therapy for CVD has hit a plateau nowadays. Thus, it is important to summarize the obstacles we are facing in this field in order to explore possible solutions for optimizing cell-based therapy and achieving real clinical application.
}

Key words: cell-based therapy, cardiovascular disease, homing, cell survival, lineage differentiation

\section{INTRODUCTION}

Cardiovascular disease (CVD), including heart diseases and stroke, is a leading cause of death worldwide, account for one-third of deaths throughout the world. ${ }^{[1,2]}$ Although conventional treatments have made a great progress in attenuating disease progression and improving quality of life, the prognosis of CVD remains poor. Over the last two decades, stem/progenitor cell-based therapeutic strategies have emerged as a promising option that may ameliorate the prognosis of CVD by repairing and replacing the damaged vascular and cardiac tissues, thereby repairing the damaged cardiac function. ${ }^{[3-5]}$ Although numerous preclinical studies showed that stem/progenitor cell treatment can markedly improve the recovery of myocardial infarction and vascular damage, the clinical efficacy of stem/progenitor cell therapy has been rather modest due to the impairment of the recruitment, survival, and regenerative capability of stem/progenitor cells in CVD patients. ${ }^{[6-8]}$ Thus, enhancement of stem/ progenitor cell function has become the focus of stem/progenitor cell research.

Numerous studies have examined a variety of stem/progenitor cells with the goal of searching for an optimized candidate for cell-based therapy to promote cardiovascular repair and regeneration for CVD. Skeletal myoblasts, bone marrowderived cells and mesenchymal stem cells were used as the cell candidates for cellbased therapies for CVD. ${ }^{[9-11]}$ Although the results from basic research are encouraging, the clinical trials revealed mixed outcomes. Until now, the application of cell-based therapy is still far from reaching satisfactory results due to the limited number of transplanted cells that actually differentiate into cardiomyocytes or endothelial cells and incorporate into damaged vessel or hearts. Hence, researchers are focusing on trying to improve the reparative abilities of transplanted cells. In this review, we will summarize the challenges we are facing in cell-based therapy and the possible ways to improve the efficacy of cell-based therapy 
in cardiovascular diseases.

\section{BARRIERS TO EFFECTIVE CELL THERAPY FOR CVD}

Cell-based therapy raised as a promising strategy for the treatment of cardiovascular disease (CVD) in the past two decades. However, despite ample evidence from the literature indicating that the transplanted cells are incorporated into the vasculature and secrete angiogenic growth factors that support the developing microvasculature, the clinical efficacy observed in these trials remains modest. ${ }^{[3,6,12]}$ Thus, it is important to summarize the obstacles we are facing in this field in order to optimize the efficacy of cell-based therapy in CVD.

The impaired homing ability of circulating progenitor cells in patients with cardiovascular diseases contributes to the poor number of cell retention in the damaged sites. Mixed cell type, inappropriate delivery routes, time and dose, which also limit the therapeutic outcomes. ${ }^{[13]}$ Studies from our and other groups showed that the CXCR4-CXCR7 expression level is lower in patient with hypertension compared with the healthy volunteers, which leads to the low efficiency of EPC homing and vascular endothelial repair. ${ }^{[14-17]}$ Gallagher et al. demonstrated that diabetes impairs EPC homing by reducing local release of SDF- $1 \alpha$ and $\mathrm{NO}$ in the sites of wound. ${ }^{[18]}$ Moreover, EPCs isolated from patients affected by T1D and T2D showed an impaired migration in the presence of SDF- $1 \alpha$ compared to the healthy control subjects. ${ }^{[19]}$ In patients with diabetes, high blood glucose causes not only a sharp decrease in the number of EPCs in the peripheral circulation, ${ }^{[20]}$ but also a decline in the ability to respond to SDF-1, migration, adhesion, and incorporation into angiogenesis sites. High blood glucose also impairs EPC proliferation and differentiation, and angiogenesis ability. ${ }^{[21,22]}$ In addition, lipid metabolism disorders cause endothelial dysfunction by impairing the number and function of EPC. Hypercholesterolemia and hypertriglyceridemia inactivate $\mathrm{NO}$ through the oxidative stress mechanism, which reduces the availability of $\mathrm{NO}$, resulting in a significant reduction in the number of circulating EPC and impaired function. ${ }^{[23]}$ Hence, it is critical for the optimization of cell-based therapy to address the defect of stem/progenitor homing in patients with cardiovascular diseases.

The ischemic and inflammatory microenvironment in the ischemic or damaged site is hostile to the survival of implanted stem/progenitor cell. Thus, most of the injected cells cannot survive because of ischemia, hypoxia, and inflammatory response. ${ }^{[2-26]}$ Heart failure patients with high circulating levels of $\mathrm{TNF}-\alpha$, a potent proinflammatory cytokine, were associated with significantly lower EPC counts as compared with patients treated with $\mathrm{TNF}-\alpha$ blocker. ${ }^{[27]}$ Human recombinant CRP, at concentrations known to predict adverse vascular outcomes, directly inhibits EPC differentiation, survival, and function, the key components of angiogenesis and the response to chronic ischemia. This occurs in part via an effect of CRP to reduce EPC eNOS expression. The ability of CRP to inhibit EPC differentiation and survival may represent an important mechanism that further links inflammation to cardiovascular disease. ${ }^{[28]}$

In addition, very few of the transplanted (or mobilized endogenous) PCs differentiate into vascular cells to achieve functional integration and long-term engraftment, and this limited potential for differentiation into endothelial-lineage cells is believed to be one of the major barriers to the success of PC therapy. ${ }^{[12,29]}$ In the ischemic myocardium, only a small portion of recruited PC attain EC phenotype and incorporate into the vessels, whereas the majority of PC remain quiescent and exert only a mild effect on neovascularization through paracrine mechanisms. ${ }^{[30]}$ One of theories is that most stem/progenitor cell, after recruited to the sites of injury, remain in a relatively quiescent and inactive state even when their regenerative activities are needed. Thus, a better understanding of how to activate stem/progenitor cell to commit to EC lineage is critical for developing more effective cell therapy.

\section{STRATEGIES TO OPTIMIZE CELL- BASED CARDIOVASCULAR REPAIR}

Although cell-based therapy in cardiovascular disease has been widely studied for two decades, the application of cell-based cardiovascular repair is limited by its low therapeutic efficacy and below expectation due to the reasons mentioned above. Therefore, researchers, including our groups, are exploring solutions to optimize cell-based therapy in CVD.

\section{Enhancing the recruitment and homing of stem/ progenitor cells}

Stem/progenitor cell recruitment and homing is a multi-step endogenous physiologic process, which involves cell migration and is important for stem/progenitor-based cardiovascular repair. It is also a therapeutic target for the enhancement of engraftment potential and reparative effect. Evidence from clinical studies demonstrated that CXCR4 signaling in endothelial progenitor cells from patients with coronary artery disease is impaired, which results in reduced neovascularization capacity of EPCs. ${ }^{[17]}$ This deficiency of EPCs may contribute to poor outcome of coronary artery disease. ${ }^{[31]}$ Accordingly, SDF-1/CXCR4 axis has emerged as a novel therapeutic target in IHD. Up-regulation of SDF-1/CXCR4 pathway 
Xu et al.: The challenges and optimization of cell-based therapy for cardiovascular disease

\begin{tabular}{|c|c|c|}
\hline Challenges for cell-based therapy & Strategies for cell-based therapy & References \\
\hline \multirow{4}{*}{$\begin{array}{l}\text { The impaired homing ability and poor number } \\
\text { of cell retention in the injured sites }\end{array}$} & Enhancing the function of SDF-1/CXCR4 axis & [32] \\
\hline & Upregulation of CXCR7 expression & [33] \\
\hline & $\begin{array}{l}\text { Overexpression of chemokines or chemokine-coated scaffold } \\
\text { implantation }\end{array}$ & {$[34,35]$} \\
\hline & Co-culture with other cells & {$[36,37]$} \\
\hline \multirow[t]{2}{*}{$\begin{array}{l}\text { The harmful ischemic and inflammatory } \\
\text { microenvironment in the damaged area }\end{array}$} & $\begin{array}{l}\text { Hypoxic preconditioning of stem/progenitor cells or administration of } \\
\text { hypoxic preconditioned autologous }\end{array}$ & {$[38,39]$} \\
\hline & Pretreatment with different molecules such as DNP and irisin & {$[40,41]$} \\
\hline \multirow{2}{*}{$\begin{array}{l}\text { Difficulty in differentiating into vascular cells } \\
\text { to function }\end{array}$} & A metabolic alternation from glycolysis to MtOP & {$[42,43]$} \\
\hline & Regulation of the function of various proteins such as E2F1 and SIRT3 & {$[44,45]$} \\
\hline
\end{tabular}

through various approaches could augment the therapeutic effect of stem/progenitor cells. Studies from our group have shown that CXCR4 gene transfer augmented EPC migration, adhesion in vitro and enhanced in vivo reendothelialization capacity of EPCs. ${ }^{[32]}$ Physical exercise attenuates ageassociated reduction in endothelium-reparative capacity of EPCs by increasing CXCR4/JAK-2 signaling. In addition, diminished CXCR7 signal also contributes to the reduced in vitro functions and in vivo re-endothelialization capacity of EPCs from hypertensive patients. ${ }^{[33]}$ Upregulation of CXCR7 expression induced by gene transfer or lercanidipine treatment increased the endothelial repair capacity of EPC in hypertension. ${ }^{[15]}$

On the other hand, overexpression of chemokines or chemokine-coated scaffold implantation at the damaged sites or target tissues to increase the recruitment of injected stem/progenitor cell had also been explored. ${ }^{[34]}$ Researchers used ROS-sensitive nanoparticles to target release CXCL12 in tissues with vascular injuries, which was shown to increase marrow stromal cell chemotaxis and homing at the target tissues. ${ }^{[3]}$ Others have attempted to modulate the homing of stem/progenitor cells by co-culture with other cells. It has been reported that co-culture CD34+ cell with porcine umbilical vein endothelial cells ex vivo can augment autologous $\mathrm{CD} 34+$ cell engraftment and reconstitution in vivo in a baboon model. ${ }^{[36,37]}$ Similar effect was also observed when co-culture bone marrow progenitor cell with primary human marrow endothelial cells in vitro in specified media conditions.

\section{Improving the survival and lineage differentiation of implanted cells}

To improve the survival of implanted cells in the hostile environment in the ischemic or damaged sites, pretreatments of stem/progenitor cells under different conditions or with various cytokines and molecules before injection were studied. Reports from both basic research and clinical trial suggest that hypoxic preconditioning of stem/progenitor cell can enhance cellular survival and therapeutic efficacy in ischemic tissues. Zhou et al. reported that hypoxic preconditioning-induced autophagy enhances the survival of engrafted endothelial progenitor cells in ischemic limb. ${ }^{[38]}$ The results from CHINA-AMI randomized controlled trial showed that intracoronary administration of hypoxic preconditioned autologous BMCs markedly improved cardiac function and remodeling in AMI patients, without increasing the occurrence of major adverse cardiovascular events. ${ }^{[39]}$

Dr. Ali and his colleagues used 2,4-dinitrophenol (DNP) pretreatment to induce chemical hypoxia via inhibiting the electron transport chain and decreasing intracellular ATP production in MSC. They found that DNP treatment can activate a series of survival, angiogenic, and cardiomyogenic factors in MSCs. Transplantation of DNP treated MSCs into infarcted rodent hearts led to an increase in cell engraftment and cardiovascular differentiation, thereby improving cardiac performance and revascularization. ${ }^{[40]}$ Zhao et al. reported that pretreated ESCs-derived Nkx2.5 CPCs with irisin, a newly identified hormone and key metabolic regulator, for 24 hours before transplantation can enhance the reparative effect of CPCs. Irisin treatment of Nkx2.5 $5^{+}$CPCs enhanced CPC-derived cardiac lineage commitment and proliferation following reintroduction into the MI heart. Furthermore, irisin also increased neovascularization in Nkx.2.5 $5^{+}$CPC-engrafted MI myocardium. CPC transplantation in the post-MI heart demonstrated an anti-apoptotic effect in MI hearts, which was augmented by irisin treatment. CPC transplantation displayed an anti-apoptotic effect in MI hearts, which was also augmented by irisin treatment. ${ }^{[4]}$

Ample evidence suggests that undifferentiated PC rely primarily on glycolysis for energy production and in order to adapt to the tremendous energy demand for biosynthesis, a metabolic alternation from glycolysis to $\mathrm{MtOP}$ is essential for cell differentiation. ${ }^{[22,43]}$ Our group have identified a novel mechanism by which E2F1, a transcription factor and classic cell cycle regulator, suppresses BM PC oxidative metabolism and endothelial differentiation through expression of the glycolysis enzymes PDK4/2. Replacement of WT BM with $\mathrm{E} 2 \mathrm{~F} 1^{-1-} \mathrm{BM}$ in mice 
significantly increases the contribution of BM PCs to new vessel formation, reduces infarct size, and improves cardiac function after MI. Thus, E2F1-mediated metabolic control impedes adult BM PCs from responding to angiogenic cues in the ischemic myocardial tissue. ${ }^{[4]}$ In addition, we and others have confirmed that SIRT3 plays a key role in the occurrence and development of vascular endothelial injury. We found that inhibition of mitochondrial oxidative damage improves re-endothelialization capacity of endothelial progenitor cells via SIRT3 (Sirtuin3)enhanced SOD2 (Superoxide Dismutase 2) deacetylation in hypertension. ${ }^{[45]}$

Cell-based therapy in cardiovascular disease has been intensively studied worldwide for over two decades. Although significant progress had been made in this field, challenges and doubts raised accompanied and limits the clinical application of cell-based therapy. To achieve successful cardiovascular repair by cell-based therapy, several major obstacles, including insufficient number of implanted stem/progenitor cell, low cell survival in the damaged tissue, and impaired reparative ability of stem/ progenitor cell in patients with cardiovascular disease, needed to be overcome. Various strategies had been employed to optimize cell-base therapy and data from our and other groups are promising. However, we are still far away from reaching the goal of developing a safe, effective, and applicable cell-base treatment for CVD. More efforts are required to further explore and optimize stem/ progenitor cell-base therapy.

\section{Conflict of Interest}

None declared.

\section{REFERENCE}

1. Lozano R, Naghavi M, Foreman K, Lim S, Shibuya K, Aboyans V, et al. Global and regional mortality from 235 causes of death for 20 age groups in 1990 and 2010: a systematic analysis for the Global Burden of Disease Study 2010. Lancet 2012; 380: 2095-128.

2. Roth GA, Johnson C, Abajobir A, Abd-Allah F, Abera SF, Abyu G, et al. Global, Regional, and National Burden of Cardiovascular Diseases for 10 Causes, 1990 to 2015. J Am Coll Cardiol 2017; 70: 1-25.

3. Afzal MR, Samanta A, Shah ZI, Jeevanantham V, Abdel-Latif A, ZubaSurma EK, et al. Use of contact force sensing technology during radiofrequency ablation reduces recurrence of atrial fibrillation: A systematic review and meta-analysis. Circ Res 2015; 117: 558-75.

4. Kalka C, Masuda H, Takahashi T, Kalka-Moll WM, Silver M, Kearney M, et al. Transplantation of ex vivo expanded endothelial progenitor cells for therapeutic neovascularization. Proc Natl Acad Sci U S A 2000; 97: 3422-7.

5. Wollert KC, Meyer GP, Muller-Ehmsen J, Tschope C, Bonarjee V, Larsen AI, et al. Intracoronary autologous bone marrow cell transfer after myocardial infarction: the BOOST-2 randomised placebo-controlled clinical trial. Eur Heart J 2017; 38: 2936-43.

6. Dimmeler S, Ding S, Rando TA, Trounson A. Translational strategies and challenges in regenerative medicine. Nat Med 2014; 20: 814-21.

7. Stamm C, Nasseri B, Choi YH, Hetzer R. Cell therapy for heart disease: great expectations, as yet unmet. Heart Lung Circ 2009; 18: 245-56.

8. Wollert KC, Drexler H. Cell therapy for the treatment of coronary heart disease: a critical appraisal. Nat Rev Cardiol 2010; 7: 204-15.

9. Hare JM, Traverse JH, Henry TD, Dib N, Strumpf RK, Schulman SP, et al. A randomized, double-blind, placebo-controlled, dose-escalation study of intravenous adult human mesenchymal stem cells (prochymal) after acute myocardial infarction. J Am Coll Cardiol 2009; 54: 2277-86.

10. Meyer GP, Wollert KC, Lotz J, Pirr J, Rager U, Lippolt P, et al. Intracoronary bone marrow cell transfer after myocardial infarction: 5-year follow-up from the randomized-controlled BOOST trial. Eur Heart J 2009; 30: 2978-84.

11. Taylor DA, Atkins BZ, Hungspreugs P, Jones TR, Reedy MC, Hutcheson $\mathrm{KA}$, et al. Regenerating functional myocardium: improved performance after skeletal myoblast transplantation. Nat Med 1998; 4: 929-33.

12. Fadini GP, Losordo D, Dimmeler S. Critical reevaluation of endothelial progenitor cell phenotypes for therapeutic and diagnostic use. Circ Res 2012; 110: 624-37.

13. Surder D, Manka R, Lo Cicero V, Moccetti T, Rufibach K, Soncin S, et al. Intracoronary injection of bone marrow-derived mononuclear cells early or late after acute myocardial infarction: effects on global left ventricular function. Circulation 2013; 127: 1968-79.

14. Liu X, Zhang GX, Zhang XY, Xia WH, Yang Z, Su C, et al. Lacidipine improves endothelial repair capacity of endothelial progenitor cells from patients with essential hypertension. Int J Cardiol 2013; 168: 3317-26.

15. Zhang XY, Su C, Cao Z, Xu SY, Xia WH, Xie WL, et al. CXCR7 upregulation is required for early endothelial progenitor cell-mediated endothelial repair in patients with hypertension. Hypertension 2014; 63: 383-9.

16. Yu BB, Zhi H, Zhang XY, Liang JW, He J, Su C, et al. Mitochondrial dysfunction-mediated decline in angiogenic capacity of endothelial progenitor cells is associated with capillary rarefaction in patients with hypertension via downregulation of CXCR4/JAK2/SIRT5 signaling. EBioMedicine 2019; 42: 64-75.

17. Walter DH, Haendeler J, Reinhold J, Rochwalsky U, Seeger F, Honold J, et al. Impaired CXCR4 signaling contributes to the reduced neovascularization capacity of endothelial progenitor cells from patients with coronary artery disease. Circ Res 2005; 97: 1142-51.

18. Gallagher KA, Liu ZJ, Xiao M, Chen H, Goldstein LJ, Buerk DG, et al. Diabetic impairments in NO-mediated endothelial progenitor cell mobilization and homing are reversed by hyperoxia and SDF-1 alpha. J Clin Invest 2007; 117: 1249-59.

19. Segal MS, Shah R, Afzal A, Perrault CM, Chang K, Schuler A, et al. Nitric oxide cytoskeletal-induced alterations reverse the endothelial progenitor cell migratory defect associated with diabetes. Diabetes 2006; 55: 102-9.

20. Krankel N, Adams V, Linke A, Gielen S, Erbs S, Lenk K, et al. Hyperglycemia reduces survival and impairs function of circulating blood-derived progenitor cells. Arterioscler Thromb Vasc Biol 2005; 25: 698-703.

21. Chen YH, Lin SJ, Lin FY, Wu TC, Tsao CR, Huang PH, et al. High glucose impairs early and late endothelial progenitor cells by modifying nitric oxide-related but not oxidative stress-mediated mechanisms. Diabetes 2007; 56: 1559-68.

22. Tepper OM, Galiano RD, Capla JM, Kalka C, Gagne PJ, Jacobowitz GR, et al. Human endothelial progenitor cells from type II diabetics exhibit impaired proliferation, adhesion, and incorporation into vascular structures. Circulation 2002; 106: 2781-6.

23. Cheng J, Cui R, Chen CH, Du J. Oxidized low-density lipoprotein stimulates p53-dependent activation of proapoptotic Bax leading to apoptosis of differentiated endothelial progenitor cells. Endocrinology 2007; 148: 2085-94.

24. Loor G, Schumacker PT. Role of hypoxia-inducible factor in cell survival during myocardial ischemia-reperfusion. Cell Death Differ 2008; 15 : 686-90.

25. Chen K, Keaney JF, Jr. Evolving concepts of oxidative stress and reactive 
oxygen species in cardiovascular disease. Curr Atheroscler Rep 2012; 14 : 476-483.

26. Liu Z, Wang H, Wang $\mathrm{Y}$, Lin Q, Yao A, Cao F, et al. The influence of chitosan hydrogel on stem cell engraftment, survival and homing in the ischemic myocardial microenvironment. Biomaterials 2012; 33: 3093-106.

27. Grisar J, Aletaha D, Steiner CW, Kapral T, Steiner S, Seidinger D, et al. Depletion of endothelial progenitor cells in the peripheral blood of patients with rheumatoid arthritis. Circulation 2005; 111: 204-11.

28. Verma S, Kuliszewski MA, Li SH, Szmitko PE, Zucco L, Wang CH, et al. C-reactive protein attenuates endothelial progenitor cell survival, differentiation, and function: further evidence of a mechanistic link between C-reactive protein and cardiovascular disease. Circulation 2004; 109: 2058-67.

29. Gu E, Chen WY, Gu J, Burridge P, Wu JC. Molecular imaging of stem cells: tracking survival, biodistribution, tumorigenicity, and immunogenicity. Theranostics 2012; 2: 335-45.

30. Sahoo S, Klychko E, Thorne T, Misener S, Schultz KM, Millay M, et al. Exosomes from human CD34(+) stem cells mediate their proangiogenic paracrine activity. Circ Res 2011; 109: 724-8.

31. Antonio N, Fernandes R, Soares A, Soares F, Lopes A, Carvalheiro T, et al. Reduced levels of circulating endothelial progenitor cells in acute myocardial infarction patients with diabetes or pre-diabetes: accompanying the glycemic continuum. Cardiovasc Diabetol 2014; 13: 101.

32. Chen L, Wu F, Xia WH, Zhang YY, Xu SY, Cheng F, et al. CXCR4 gene transfer contributes to in vivo reendothelialization capacity of endothelial progenitor cells. Cardiovasc Res 2010; 88: 462-70.

33. Xia WH, Li J, Su C, Yang Z, Chen L, Wu F, et al. Physical exercise attenuates age-associated reduction in endothelium-reparative capacity of endothelial progenitor cells by increasing CXCR4/JAK-2 signaling in healthy men. Aging Cell 2012; 11: 111-9.

34. Narita A, Takahara M, Sato D, Ogino T, Fukushima S, Kimura Y, et al. Biodegradable gelatin hydrogels incorporating fibroblast growth factor 2 promote healing of horizontal tears in rabbit meniscus. Arthroscopy 2012, 28: 255-63.

35. He F, Luo PF, Tang T, Zhang F, Fang H, Ji SZ, et al. Targeted release of stromal cell-derived factor-1alpha by reactive oxygen species-sensitive nanoparticles results in bone marrow stromal cell chemotaxis and homing, and repair of vascular injury caused by electrical burns. PLoS One
2018; 13: e0194298.

36. Brandt JE, Bartholomew AM, Fortman JD, Nelson MC, Bruno E, Chen $\mathrm{LM}$, et al. Ex vivo expansion of autologous bone marrow CD34(+) cells with porcine microvascular endothelial cells results in a graft capable of rescuing lethally irradiated baboons. Blood 1999; 94: 106-13.

37. Gori JL, Butler JM, Kunar B, Poulos MG, Ginsberg M, Nolan DJ, et al. Endothelial Cells Promote Expansion of Long-Term Engrafting Marrow Hematopoietic Stem and Progenitor Cells in Primates. Stem Cells Transl Med 2017; 6: 864-76.

38. Zhou P, Tan YZ, Wang HJ, Wang GD. Hypoxic preconditioning-induced autophagy enhances survival of engrafted endothelial progenitor cells in ischaemic limb. J Cell Mol Med 2017; 21: 2452-64.

39. Hu X, Huang X, Yang Q, Wang L, Sun J, Zhan H, et al. Safety and efficacy of intracoronary hypoxia-preconditioned bone marrow mononuclear cell administration for acute myocardial infarction patients: The CHINAAMI randomized controlled trial. Int J Cardiol 2015; 184: 446-51.

40. Ali A, Akhter MA, Haneef K, Khan I, Naeem N, Habib R, et al. Dinitrophenol modulates gene expression levels of angiogenic, cell survival and cardiomyogenic factors in bone marrow derived mesenchymal stem cells. Gene 2015, 555: 448-57.

41. Zhao YT, Wang J, Yano N, Zhang LX, Wang H, Zhang S, et al. Irisin promotes cardiac progenitor cell-induced myocardial repair and functional improvement in infarcted heart. J Cell Physiol 2019; 234: 1671-81.

42. Crespo FL, Sobrado VR, Gomez L, Cervera AM, McCreath KJ. Mitochondrial reactive oxygen species mediate cardiomyocyte formation from embryonic stem cells in high glucose. Stem Cells 2010; 28: 1132-42.

43. Folmes CD, Nelson TJ, Martinez-Fernandez A, Arrell DK, Lindor JZ, Dzeja PP, et al. Somatic oxidative bioenergetics transitions into pluripotency-dependent glycolysis to facilitate nuclear reprogramming. Cell Metab 2011; 14: 264-271.

44. Xu S, Tao J, Yang L, Zhang E, Boriboun C, Zhou J, et al. E2F1 Suppresses Oxidative Metabolism and Endothelial Differentiation of Bone Marrow Progenitor Cells. Circ Res 2018; 122: 701-11.

45. He J, Liu X, Su C, Wu F, Sun J, Zhang J, et al. Inhibition of Mitochondrial Oxidative Damage Improves Reendothelialization Capacity of Endothelial Progenitor Cells via SIRT3 (Sirtuin 3)-Enhanced SOD2 (Superoxide Dismutase 2) Deacetylation in Hypertension. Arterioscler Thromb Vasc Biol 2019; 39: 1682-98.

How to cite this article: $\mathrm{Xu} \mathrm{S}$, Qiu Y, Tao J. The challenges and optimization of cell-based therapy for cardiovascular disease. J Transl Intern Med 2021; 9: 234-8. 